\title{
STUDIES ON THE VELOCITY OF BLOOD FLOW
}

\author{
VIII. The Velocity of Blood Flow and Its Relation to Other \\ Aspects of the Circulation in Patients with \\ PULMONARY EMPHYSEMA ${ }^{1}$
}

BY SOMA WEISS AND HERRMANN L. BLUMGART

(From the Thorndike Memorial Laboratory, Boston City Hospital and the Department of Medicine, Harvard Medical School)

(Received for publication July 18, 1927)

Pulmonary emphysema frequently presents one of the most perplexing problems of differential diagnosis in clinical medicine because the cardinal symptoms, dyspnea, cough, and cyanosis are characteristic also of circulatory insufficiency. In many patients, the history and signs of cardiac pathology enable one to make a diagnosis of cardiovascular disease with confidence; but in others, with little or no evidence of heart disease and with no signs of peripheral congestion, the problem arises as to whether the dyspnea of the patient is due to early myocardial failure or to the disordered gaseous exchange of pulmonary emphysema. Frequently, the problem is still further complicated by the simultaneous presence of both conditions. It then becomes a matter of considerable clinical importance to estimate the relative significance of these two conditions in producing the cough, dyspnea, and lowered vital capacity, because proper treatment and accurate prognosis require such differentiation (1).

Unfortunately, our knowledge of the underlying pathological physiology of pulmonary emphysema, upon which rational diagnosis and therapeutics must be based, is incomplete. Studies on the circulation in patients suffering from pulmonary emphysema are especially lacking since direct measurement of the blood flow through the lungs has hitherto been impossible, and because other data on

1 This study was aided by a grant from the Proctor Fund of the Harvard Medical School for the Study of Chronic Diseases, and from the De Lamar Mobile Research Fund of Harvard University. 
the circulation in emphysema are scanty. Our understanding has been based, therefore, mainly on experiments on animals, on clinical observations, and on post mortem findings. The possibility of obtaining information of the rôle of circulatory failure in emphysema is considerably enhanced by direct measurements of the velocity of blood flow according to a method which has recently been devised.

\section{RESUMÉ OF LITERATURE ON THE INFLUENCE OF MECHANICAL FACTORS IN ALTERING BLOOD FLOW IN PULMONARY EMPHYSEMA}

The factors which may influence the circulation in emphysema may be classified into four groups according to Fraenkel (2) and Stähelin (3): (1) increased inspiratory position of the lungs; (2) increased intra-alveolar pressure; (3) obliteration of the pulmonary capillaries; (4) alterations in rate and depth of respiration. Since the first and fourth points are closely related, they will be discussed together.

\section{1 and 4. The influence of distention of the lungs and of alterations in rate and depth of respiratory movements on the pulmonary circulation}

The effect of distention of the lungs on pulmonary blood flow has interested both physiologists and clinicians for a long time. Although considerable work has been accomplished, the effect of increased expansion of the lung on the pulmonary circulation is not definitely established. In 1903, Tigerstedt (4), reviewing the available data, concluded that the blood flow through the lungs increases during inspiration. Similarly, Lohmann and Müller (5), in 1913, experimenting on excised lung tissue, concluded that distention of the lungs permitted increased blood flow. Cloetta (6), on the basis of experiments on animals and later observations on models of pulmonary vessels, concluded that there is no essential change in blood flow during normal inspiration. In pathological respiration, however, such as in shallow, rapid breathing, the blood flow is increased, while with slow and deep respiration, such as may occur in emphysema, there is a decrease in blood flow.

The relationship between pulmonary ventilation and the minute volume output of the heart in dogs was studied recently by Marshall (8). He found no changes in the minute volume output of the heart when the ventilation showed a change of 100 per cent or more. Similarly, Drinker, Churchill, and Ferry (9) found "little variation in pulmonary blood volume under different conditions of the respiration."

In a considerable number of patients suffering from emphysema respiratory movements are rather deep, because the increase in rate is not proportional to the increase in minute volume of respiration. Stähelin and Schutze (10) found the total minute volume of the respiration averaged 10.1 liters in patients suffering from emphysema, in contrast to 7.6 liters in normal subjects. 


\section{The effect of increased intra-alveolar pressure}

The intra-alveolar pressure may become abnormally high during expiration with narrowing of the small bronchioles, as in bronchial asthma and bronchitis; or with forceful and short expiration, as in cough. Such increased intrathoracic pressure may embarrass pulmonary blood flow considerably. V. Rohden (11) has shown experimentally that the capacity of the pulmonary capillaries is directly influenced by the intra-alveolar pressure. With increase in the intra-pulmonary pressure he observed a decrease in the pulmonary blood flow. If pulmonary emphysema is associated with bronchial asthma, or chronic bronchitis, it is probable that intra-pulmonary pressure is, at least temporarily, high. The significance of this factor has received considerable theoretical consideration by a number of clinicians in the past.

\section{The effect of obliteration of the capillaries of the lungs on the pulmonary circulation}

Whether, as a result of atrophy and rupture of alveoli, sufficient obliteration of the pulmonary capillaries occurs to cause increased pulmonary resistance is unsettled. Lichtheim (12), as early as 1876 , observed no appreciable change in the pressure in the small and large circulation, following the ligation of one pulmonary artery. Similarly, Drinker, Churchill, and Ferry (9) recently demonstrated that, after occlusion of the left branch of the pulmonary artery, the right lung gives free passage to the pulmonary blood, even when cardiac inflow is greatly increased. On the other hand, after occlusion of the right branch of the pulmonary artery, a diminution in the aortic output appears at once. It is, of course, questionable whether such acute experiments conducted in animals at rest under deep anesthesia bear at all on the significance of the "vascular reserve" of the lung, which, under exercise, may be essential and fully needed. The presence of hypertrophy of the right ventricle in pulmonary emphysema is often cited as evidence for increased pulmonary resistance following obliteration of capillaries. The significance of this observation is not as yet clear, for carefully analyzed autopsy material, showing the frequency and intensity of such changes in the cardiac muscle, is still lacking. Conclusions from bedside or roentgenological observations are unsafe, because, as Stähelin (3) points out, the hearts of emphysematous patients tend to assume a transverse position and, by $x$-ray, may easily be mistaken for hypertrophied hearts. Such was, indeed, the case in one of our patients in whom, as will be seen below, the orthodiagram showed enlargement and in whom the weight of the heart, post mortem; was within normal limits. Nevertheless, even if hypertrophy of the right ventricle does occur constantly in emphysema, it would not necessarily indicate increased pulmonary resistance. The muscular hypertrophy might be due to increased work in maintaining a high minute volume flow in an attempt to compensate for the insuffcient ventilation. 
Venous pressure measurements might be expected to throw light, not only on the condition of the peripheral venous flow, but also on pressure relations within the thorax. Were it not that these two factors may influence venous pressure in opposite directions, the significance of the venous pressure measurements would be greater.

The significance of a diminished vital capacity in most patients with pulmonary emphysema is not clear. Such a lowering may be due to pulmonary distention with loss of pulmonary elasticity, to chronic passive congestion, or to both. While symptoms, such as weakness, cyanosis, and dyspnea appear in some patients with a diminished vital capacity, in others identical or more intense symptoms may be associated with a normal vital capacity. It is, therefore, doubtful whether the clinical pathology of emphysema may be explained in every case on the basis of disturbed external ventilation.

Measurements of the minute volume output of the heart would greatly aid our understanding of the circulation in emphysema. Unfortunately, all methods available for such measurements postulate equilibrium between alveolar air and blood, the very relationship most seriously disturbed in this condition. Dreser (13) and Beitzke (14) were aware of this difficulty. According to them, the disturbance is due to change in the physical characteristics of the alveolar walls. On the basis of theoretical considerations, studies of post mortem preparations, and experiments on glass models, they conclude that changes in the shape of the alveoli and infundibula interfere markedly with the diffusion of gases within the alveoli. This disturbance, according to these authors, is of great importance. Fortunately, an objective method for studying the velocity of blood flow through the lungs has been devised, which, unlike the methods for studying the minute volume flow, does not depend upon gaseous equilibrium between blood and alveolar air. Since previous observations have been concerned only indirectly with the dynamics of the circulation in pulmonary emphysema and since practically no direct measurements were available, the following investigation was undertaken.

\section{THE METHODS USED}

Preceding studies (15) (16) have shown the feasibility of intravenous injection of radium $C$ for the measurement of the "arm to arm circulation time" in normal subjects, as well as in patients with cardiovascular disease. The method appeared particularly suited to the study of pulmonary emphysema, because, in contrast to minute volume methods, it neither postulates normal gaseous exchange nor requires coöperation on the part of the patients. The "arm to arm circulation time," however, as pointed out previously, includes the arterial and venous blood flow times, and the pulmonary circulation time; the latter being of the greatest significance in emphysema. 
In order to measure the velocity of blood flow within the lesser circuit, the method used was that previously described (15) (16). This method measures, not only the pulmonary circulation time, but also, simultaneously, the velocity of venous flow from the elbow to the right auricle.

All the measurements were obtained under basal metabolic conditions. The pulse rate was counted several times before and after the test. The venous pressure was measured according to the method of Moritz and Tabora. All patients were in the hospital and so their clinical condition could be carefully studied.

The abnormal physical signs, on which the diagnosis of emphysema was based, were barrel-shaped chest, low borders of the lungs, marked fixation of the thorax, obliteration of cardiac dulness, and limited excursion of the lower borders of the lungs. The severity of emphysema in the patients varied considerably. Some exhibited dyspnea and weakness only on exertion and a low vital capacity at rest. Other patients showed marked dyspnea, orthopnea, cyanosis, retraction of the lower ribs, and narrowing of the costal angle on inspiration (Hoover) (17). The etiological factors varied. Some of the patients were suffering from long standing bronchial asthma, others from chronic bronchitis. Some patients did not have any pulmonary infection, but, as a result of changes in the bony thorax and in the excursions of the lungs, had low vital capacities and clinical evidence of "ventilatory insufficiency." A short summary of the clinical findings of the patients is given below.

\section{RESULTS}

Table 1 presents the findings in twenty-one of the twenty-five patients studied. In these patients the velocity of blood flow was within normal limits. The ages of these patients varied from twenty-five to seventy years although most of them were between forty and fifty years of age. The clinical condition of patients in this group varied considerably. Some complained of weakness and dyspnea only on exertion, others suffered from intense dyspnea and cyanosis at rest resulting in complete restriction of muscular activity. Chronic bronchitis, bronchial asthma, and structural and functional changes in the thorax appeared to play a predominant 


\begin{tabular}{|c|c|c|c|c|c|c|c|c|}
\hline$\vec{z}$ & 离 & wIe of wry & 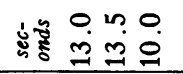 & $\stackrel{0}{\circ}$ & 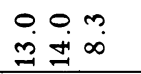 & $\stackrel{9}{9}$ & 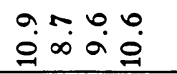 & $\stackrel{\infty}{0}$ \\
\hline है & 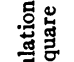 & Sreuour nd $_{d}$ & ذँّ & & & & & \\
\hline$s$ & 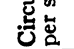 & ұлеәч о7 шлу & ذั่ & & & & & \\
\hline 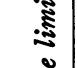 & $\tilde{E}$ & WIE of way & பี & 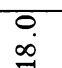 & 0.0 & $\begin{array}{l}0 \\
2\end{array}$ & $\begin{array}{llll}0 & 0 & 0 & 0 \\
0 & \infty & -1 & 0\end{array}$ & $\stackrel{0}{=}$ \\
\hline $\begin{array}{c}5 \\
5 \\
5\end{array}$ & 蒫 & Kseuour $\mathrm{n}_{\mathrm{d}}$ & $\dot{d}$ & & & & & \\
\hline కิ & 节 & ұлеәч of шіу & $\dot{\varpi}$ & & & & & \\
\hline$\frac{3}{3}$ & & рәุวэ! & 急急的 ? & 0 & $0=0$ & $\stackrel{1}{n}$ & $a \infty \not i n$ & $\ddot{m}$ \\
\hline 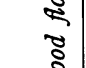 & & 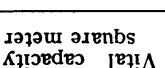 & ن 옴용요 & ๙్ర & 웡융요 & 品 & 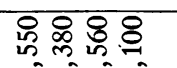 & 옥 \\
\hline ১ & & 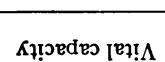 & ن & 8 & 京总要 & 용 & 융유윰 & 응 \\
\hline & & गо1sera & $=00$ & t & ง & + & $\sim \oslash \infty \infty$ & $\infty$ \\
\hline ま & 焉 & ग![O¥ऽאS & 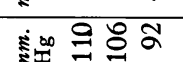 & at & $\tilde{\Xi} \cong$ & హ゙ & $\exists \cong 90$ & $\Xi$ \\
\hline हू & & arnssadd snouə $\Lambda$ & : & $\stackrel{\infty}{-}$ & 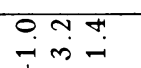 & $\stackrel{0}{0}$ & 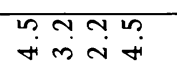 & $\stackrel{i}{i}$ \\
\hline & & вәде әวвјлnS & 중ำ & N & $\widehat{\sigma} 7 \sigma$ & లి & 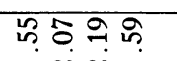 & 눙 \\
\hline हूँ & & $\partial s n_{A}$ & ๓กิ & 0 & む゙苟 & $\sim$ & $\infty \sim-n$ & 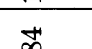 \\
\hline 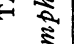 & & & $\sim \sim \infty$ & 0 & ONN & 0 & $\infty \quad 0 N 4$ & $\infty$ \\
\hline & & әมกวยมวduว $\mathrm{L}$ & ลิล人 & $\hat{a}$ & $\infty \infty$ & 8 & $\hat{a} \approx \approx \circ$ & $\hat{a}$ \\
\hline 8 & & $2 \Omega_{\mathrm{V}}$ & テテ朵 & $\stackrel{2}{\sim}$ & 矛孚 & F & बे in in ले & $\stackrel{2}{2}$ \\
\hline 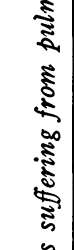 & & 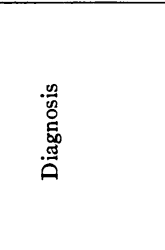 & 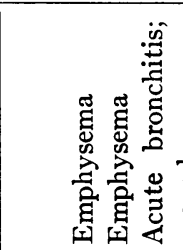 & 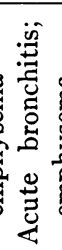 & 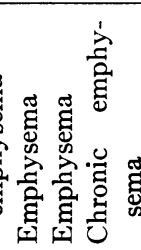 & 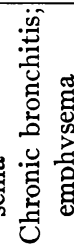 & 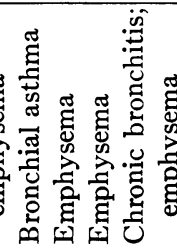 & 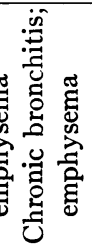 \\
\hline 苋 & & 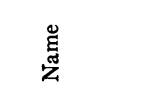 & 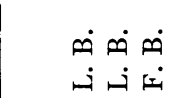 & $\dot{\varphi}$ & $\begin{array}{l}\dot{\theta} \dot{\theta} \\
\dot{n} \dot{B}\end{array}$ & 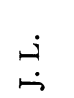 & 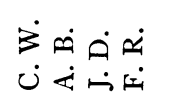 & ن \\
\hline 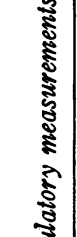 & & 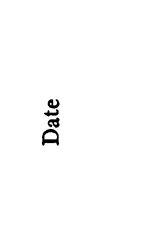 & 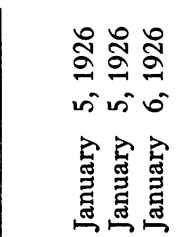 & 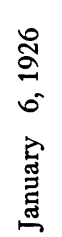 & 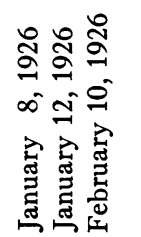 & 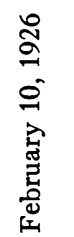 & 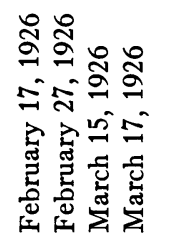 & 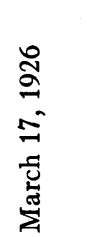 \\
\hline । & & เsว fo raqun $_{N}$ & ద & $\mathscr{7}$ & न्म & 2 & 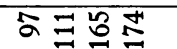 & $\stackrel{2}{=}$ \\
\hline
\end{tabular}




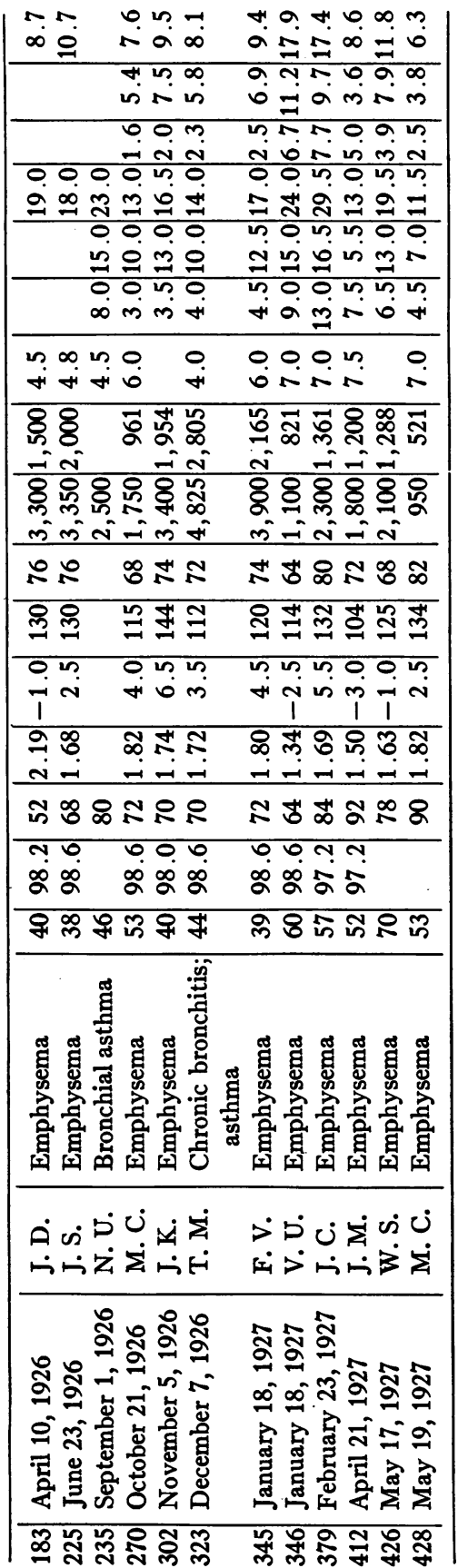


rôle in the etiology of emphysema in this group. The normal or even increased velocity of blood flow, particularly in those patients who had many of the symptoms and signs of severe circulatory failure, such as conspicuous weakness, cyanosis, and dyspnea, is of great importance. It shows that pulmonary emphysema alone is sufficient for the production of these symptoms and signs. In some patients the velocity of blood flow was greater than that usually found in normal individuals. As an example of the latter finding, we wish to call attention to the observations on M. C. $(270,428)$. This patient, as the appended summary of this clinical condition indicates, was suffering from severe emphysema and bronchial asthma of twentysix years' duration. Although his vital capacity was only $1750 \mathrm{cc}$. (961 cc. per square meter of body surface) at time of the first measurement, and $950 \mathrm{cc}$. (521 cc. per square meter) six months later at time of the second test, the crude pulmonary circulation time was $\mathbf{1 0 . 0}$ seconds on the first occasion, and 7.0 seconds at time of the second test when his general condition was worse.

Severe pulmonary emphysema, therefore, does not necessarily obstruct the blood flow sufficiently to interfere with the normal velocity of blood flow. On the contrary, in some patients increased speed of blood through the lungs may be present. On the basis of the facts now available, one cannot say whether the normal or increased velocity observed in these patients is maintained with or without aid of the cardiac reserve. Circulation and ventilation are closely related physiological mechanisms in the human body. The significance of hyperventilation in compensating for circulatory failure is fully appreciated. A reverse relation between circulation and ventilation possibly exists in what we may term "ventilatory failure" (emphysema).

With two exceptions, the vital capacities of the patients were moderately or greatly reduced. The average vital capacity of twenty-five patients was $1583 \mathrm{cc}$. per square meter of body surface (normal $2376 \mathrm{cc}$.). This lowered vital capacity corresponds to that observed in patients who, as a result of arteriosclerotic heart disease with fibrillation of the auricles, complained of dyspnea but showed no congestive failure at the time of test.

The average venous pressure of twenty-four patients of this group was $6.8 \mathrm{~cm}$., which is slightly lower than $7.3 \mathrm{~cm}$., the average venous pressure of sixty-five normal subjects. 
Comparison of the vital capacities with the symptoms and signs indicates no necessary correspondence between reduction in the vital capacity and the clinical condition of the patient. If one considers that pulmonary emphysema is not a morphological or etiological entity, but is rather a state of "ventilatory insufficiency" due to faulty gaseous exchange, one easily understands this lack of parallelism. We observed in a few patients, C. W. (97) and T. M. (323), normal, or even high, vital capacities with unmistakable clinical evidence of "ventilatory insufficiency" and without evidence of cardiac pathology. It is in such patients, as Dresers (13) and Beitzke (14) point out, that the disturbance in gaseous exchange does not depend upon the impaired movement of the lungs or upon the diminution of air space, but rather upon physico-chemical characteristics of the alveolar wall which govern the diffusion of gases. When one considers the numerous factors in the production of emphysema which vary in relative importance from case to case, there is no reason to expect a uniform correlation between the morphology of the lungs and the clinical condition of the patient. This concept of pulmonary emphysema suggests that the degree of ventilatory insufficiency indicated by clinical symptoms and signs is associated with corresponding changes in the carbon-dioxide and oxygen content of the blood. Such measurements in uncomplicated emphysema may possibly offer, therefore, a quantitative index of the degree of physiological disturbance manifested by these patients (18).

The venous pressures of patients of table 1 were within normal limits. This finding indirectly confirms the fact that no severe failure of the right chambers of the heart was present.

Table 2 presents measurements on the four patients suffering from emphysema in whom the velocity of blood flow was slightly slower than normal. In patients in whom both the venous and the pulmonary blood flow were measured, the average time of the venous flow was 9.5 seconds, and, although these patients were completely. disabled, the average velocity of blood flow through the lungs was only: moderately prolonged (18.9 seconds). If we compare the average prolongation with that observed in patients suffering from cardiovascular disease, we find that the retardation of blood flow was less than that in patients with arteriosclerosis, who had never exhibited congestive failure and whose only complaint was dyspnea on exertion. 
While such slowing of the blood flow in patients with cardiovascular disease was associated with but slight restriction of muscular activity, the patients with pulmonary emphysema were completely incapacitated. The signal symptoms and signs shown by these patients are due, therefore, only to a slight extent to changes in the blood flow. Observations on J. C. (335) are of importance as we have had an opportunity to follow her condition closely and correlate our findings with post mortem examination. This patient suffered from the extreme form of the disease. The velocity of blood flow was measured only two months before her death, which was directly due to emphysema (see appended note, p. 569). She also showed myocardial failure, as judged from pitting edema around the ankles, but the crude pulmonary circulation time was only 19.5 seconds. The dyspnea, retraction of the lower ribs on inspiration, and the weakness cannot be explained on the basis of the retardation in blood flow. The fact that this patient practically choked to death with but slight slowing of the blood stream, and the fact that other patients with emphysema did not show marked slowing, suggests that with the defective aeration of blood due to ventilatory insufficiency such as is present in emphysema, conspicuous reduction in blood flow due to cardiac failure would probably be incompatible with life. This may also explain why elderly people with a tendency to emphysema and with cardiovascular disease show a more severe disturbance in bodily function than one would expect from the cardiovascular damage alone. This observation was mentioned in a previous communication.

The average vital capacity of patients in this group (table 2) was $1752 \mathrm{cc}$. (average of four measurements), or $812 \mathrm{cc}$. (average of two measurements) per square meter of body surface. This is a lower average than that observed in a group of cardiac patients with the most marked decompensation. The average of the venous pressures was $10.6 \mathrm{~cm}$. This pressure is slightly higher than the average 7.3 cm., venous pressure of sixty-five normal subjects. The fact that most patients with marked pulmonary emphysema and with normal velocity of blood flow showed normal or slightly low venous pressures, and that others with slight prolongation of blood flow showed slightly increased venous pressures, indicates that pulmonary emphysema per se is not associated with increased venous pressure. If, there- 


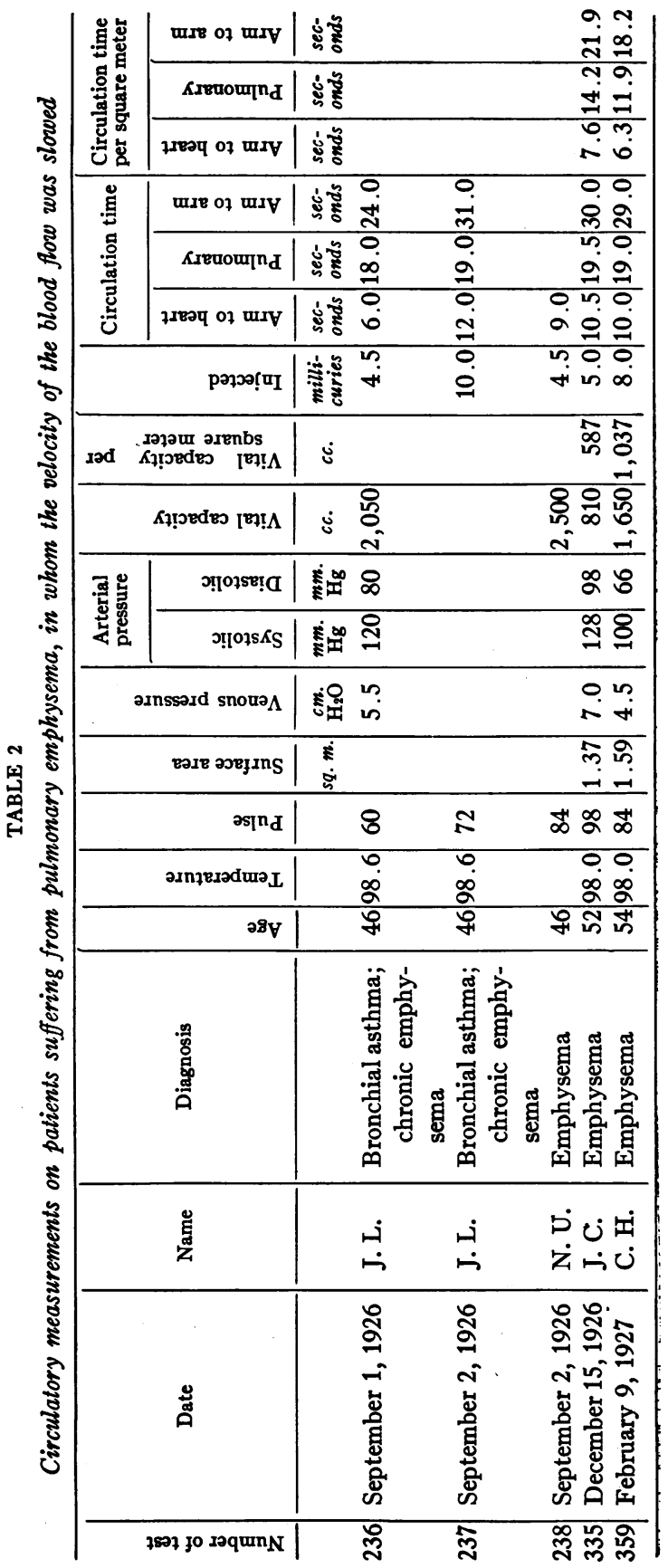


fore, a patient with chronic pulmonary emphysema has a high venous pressure, cardiac pathology should in addition be suspected. Because the clinical signs and symptoms of the patient may not aid in differentiating emphysema from myocardial failure, and furthermore, because emphysema and myocardial failure may be present in the same patient; in the estimation of the relative degree of pulmonary and cardiac disease, combined measurements of the vital capacity, venous pressure, and pulmonary blood flow may be of great diagnostic importance.

\section{SUMMARY AND CONCLUSIONS}

1. Clinical studies and measurements of the velocity of blood flow, of the vital capacity of the lungs, and of the venous pressure are presented in twenty-five patients with pulmonary emphysema.

2. The arm to arm and pulmonary circulation times were within normal limits in all but four patients.

3. The vital capacity was definitely reduced in all but seven patients.

4. The venous pressure was within normal limits in all patients.

5. In the group of twenty-one patients in which the velocity of blood flow was within normal limits, the arm to arm circulation time averaged 18.6 seconds (normal, 17.5 seconds), the velocity of venous blood from the arm to the heart, 6.4 seconds (normal, 6.6 seconds), the crude pulmonary circulation time 11.8 seconds (normal, 10.8 seconds), and the actual pulmonary circulation time 7.6 seconds (normal 6.5 seconds). The vital capacities of this group averaged $1583 \mathrm{cc}$. (normal, $2376 \mathrm{cc}$.) per square meter of body surface, and the venous pressure, $6.8 \mathrm{cc}$. of water (normal, $7.3 \mathrm{~cm}$.)

6. The observations reported demonstrate that even severe, chronic pulmonary emphysema does not necessarily obstruct the blood flow sufficiently to interfere with normal velocity of blood flow through the lungs. On the contrary, in some patients with emphysema the velocity of blood flow is increased. This increase in the velocity of blood flow through the lungs may be an effort on the part of the circulatory system to compensate for deficient ventilation, in which case it would be another expression of the close interrelation between the cardiovascular and ventilatory systems. 
7. Our investigation does not indicate whether the circulation in emphysema is maintained with or without aid of the cardiac reserve.

8. In the group of four patients who showed a slightly retarded blood flow, the arm to arm circulation time averaged 28.5 seconds (normal, 17.5 seconds), the venous velocity time, 9.5 seconds (normal, 6.6 seconds), the crude pulmonary circulation time, 18.9 seconds (normal, 10.8 seconds), and the calculated actual pulmonary circulation time averaged 14.2 seconds (normal, 6.5 seconds). The average vital capacity was $1752 \mathrm{cc}$. or $812 \mathrm{cc}$. per square meter of body surface (normal, $2376 \mathrm{cc}$. per square meter), and the average venous pressure, $10.6 \mathrm{~cm}$. (normal, $7.3 \mathrm{~cm}$.).

9. Since our experience shows that in most patients with marked pulmonary emphysema, the venous pressure and the velocity of blood flow are normal, we believe that in the small group of four patients in which the blood flow was slightly retarded and the venous pressure elevated, pulmonary emphysema was complicated by circulatory failure.

10. Clinical emphysema is not necessarily based on morphological changes in the lungs but is often a purely functional entity. Hence, correlation between pathological findings and clinical signs and symptoms is not always to be expected.

11. Because changes in the bony thorax, in the excursions of the lungs, or in the structure of the bronchi, bronchioles and alveoli may lead to identical functional consequences, and because analysis of the relative importance of these etiological factors is often difficult, we suggest, instead of emphysema, the term "ventilatory insufficiency" as a diagnostic group characteristic.

12. In differentiating between "ventilatory" and cardiac insufficiency, and, when both are present, in evaluating their relative signifcance, combined measurements of the vital capacity, venous pressure, and the velocity of peripheral and pulmonary blood flow may be of great diagnostic importance.

We are indebted to Dr. Francis W. Peabody for his helpful suggestions and to Mrs. Elizabeth Hall for her assistance in the investigation. 


\section{BIBLIOGRAPHY}

1. Peabody, F. W., Med. Clin. N. America, 1925, viii, 1431. Clinical Aspects of Pulmonary Emphysema.

2. Fränkel, A., Berlin, 1904. Spezielle Pathologie und Therapie der Lungenkrankheiten.

3. Stähelin, R., Ergebn. d. inn. Med. u. Kinderh., 1915, xiv, 516. Pathologie, Pathogenese und Therapie des Lungenemphysem.

4. Tigerstedt, R., Ergebn. d. Physiol., 1903, ii, 528. Der kleine Kreislauf.

5. Lohmann, A., and Müller, E., Zitsungb. der Gesellsch. zur Beförd. d. ges. Naturwissenschaften zu Marbung, 1913, No. 4, 165. UUber Durchblutung der Lungen in verschiedenen Dehnungszustanden.

6. Cloetta, M., Arch. f. Exper. Path. u. Pharmak., 1912, lxx, 407. In welcher Respirationsphase ist die Lunge am besten durchblutet?

7. Cloetta, M., Arch. f. d. ges. Physiol., 1913, clii, 339. Untersuchungen über die Elastizität der Lunge und deren Bedeutung für die Zirkulation.

8. Marshall, E. K., Am. J. Physiol., 1926, lxxvii, 459. Studies on the Cardiac Output of the Dog. I. The Cardiac Output of the Normal Unanesthetized Dog.

9. Drinker, C. K., Churchill, E. D., and Ferry, R. M., Am. J. Physiol., 1926, lxxvii, 590. The Volume of Blood in the Heart and Lungs.

10. Stähelin, R., and Schütze, A., Ztschr. f. klin. Med., 1912, lxxv, 15. Spirographische Untersuchungen an Gesunden, Emphysematikern, und Asthmatikern.

11. v. Rhoden, F., Deutsches Arch. f. klin. Med., 1913, cix, 383. Zur Blutzirkulation in der Lunge bei geschlossenem und offenem Thorax und deren Beeinflussung durch Uber- und Unterdruck.

12. Lichtheim, L., Berlin, 1876. Die Störungen des Lungen-Kreislaufes und der Einfluss auf den Blutdruck.

13. Dreser, H., Ztschr. f. d. ges. exp. Med., 1922, xxvi, 223. Die Bewegung der Atemluft in den Alveolorgängen der Lungen.

14. Beitzke, H., Deutsches Arch. f. klin. Med., 1925, cxlvi, 91. Zur Mechanik des Gaswechsels beim Lungenemphysem.

15. Blumgart, H. L., and Weiss, S., J. Clin. Invest., 1927, iv, 15. Studies on the Velocity of Blood Flow. II. The Velocity of Blood Flow in Normal Resting Individuals and a Critique of the Method Used.

16. Blumgart, H. L., and Weiss, S., J. Clin. Invest., 1927, iv, 399. Studies on the Velocity of Blood Flow. VII. The Pulmonary Circulation Time in Normal Resting Individuals.

17. Hoover, C. F., J. A. M. A., 1926, lxxxvii, 813. The Bedside Study of Air Hunger.

18. Scott, R. W., Arch. Int. Med., 1920, xxvi, 544. Observations on the Pathologic Physiology of Chronic Pulmonary Emphysema. 


\section{APPENDIX}

\section{Abstracts of Histories and Physical Examinations of Patients with Pulmonary EMPHYSEMa}

335. J. C.: This patient's condition is given in greater detail because she manifested the extreme severity of pulmonary emphysema and because we were able to perform a post-mortem examination. She may serve therefore as an illustration of the extreme manifestation of the disease. Ever since 1915 she had been suffering from increasing dyspnea. This was always present during exertion but showed marked fluctuation on different occasions. As a child she suffered from empyema. In 1919 she attended the Outpatient Department of the Massachusetts General Hospital where physical examination was normal except that respiratory sounds were diminished. Occasional râles were heard. The sputum was negative for tubercle bacilli. X-ray examination showed diffuse thickening of the lung markings extending outward from the roots. Area of the right apex showed absence of lung markings.

In 1920 she was admitted to the Boston City Hospital complaining of weakness and periodic attacks of dyspnea. The chest was hyperresonant and the breath sounds were distant. During this period an x-ray picture of chest showed pneumothorax. In 1925 fluoroscopic examination showed that both lung fields were extremely large. The diaphragm was low and flat on both sides with practically no respiratory movement present. Heart shadow was small. Appearance was that of emphysema and pulmonary fibrosis.

She was readmitted to the Boston City Hospital November 26, 1926, this time being forced to go to bed on account of weakness. Her feet had become swollen during the preceding three weeks and there was marked dyspnea and orthopnea. The face, lips and fingers were markedly cyanotic. The accessory respiratory muscles were active in respiration. There was wheezing with markedly prolonged expiration. The thorax was unusually long and narrow. Level of diaphragm was very low and showed no excursion with interrupted deep breathing. The chest was tympanitic and the respiratory sounds were distant. Scattered râles and rhonchi were heard, particularly over the upper part of the chest. The lower ribs and costal border line moved toward the median line with inspiration (positive Hoover's sign). The heart was $11.5 \mathrm{~cm}$. from the midline in the fifth intercostal space. The sounds were distant. There was slight pitting edema over both ankles. While in the hospital, patient showed considerable variations in intensity of dyspnea, cyanosis and type of breathing. The behavior of the lower ribs and the costal angle showed corresponding changes. Digitalis did not produce definite improvement. At time of test, the cyanosis was marked and dyspnea was intense, and patient was able to recline even at $45^{\circ}$ only for one or two minutes at a time.

The specific gravity of the urine was 1010 to 1032 . There was a slight trace of albumin. The phthalein renal function test was 30 to 35 per cent in two hours. 
Blood pressure was 120 to $130-80$ to 98 . The Kahn blood test was repeatedly negative. The blood urea nitrogen was $37.3 \mathrm{mg}$. per $100 \mathrm{cc}$. of blood. The hemoglobin was 75 to 85 per cent. Sputum was repeatedly negative for tubercle bacilli.

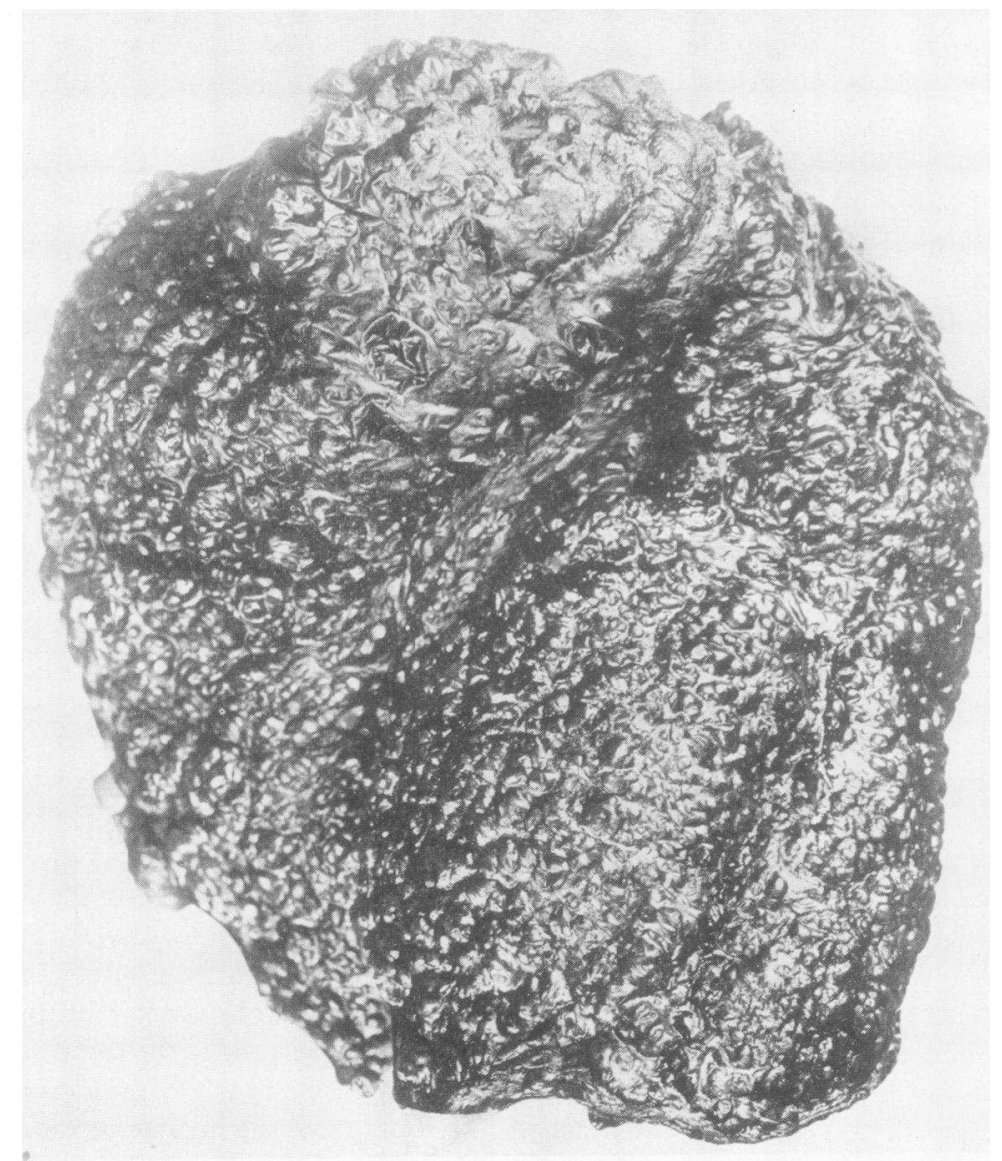

Fig. 1. Gross Post-mortem Appearance of the Right Lung in Patient J. C. (No. 335)

The surface of the lung is granular due to innumerable vesicles. On the left margin several large blebs are visible.

$\mathrm{X}$-ray and fluoroscopic examination of the chest showed a low and flat diaphragm with slight movements only. There was slight diffuse fibrosis throughout the lungs. 
Temperature 97 to $100^{\circ}$; pulse 80 to 100 ; respiration 20 to 25 .

Patient gradually grew weaker, the dyspnea and orthopnea increased, and she did not respond to medication. On February 21 she died. Except for the effect of morphine she was conscious to the end and she actually choked to death.

The post-mortem examination showed moderate pitting edema of the extremities. The diaphragm was at the level of the seventh rib on the right. The heart weighed 320 grams. The chambers were moderately dilated. Both lungs were unusually large; surface coarsely granular, consisting of small rounded elevations from $0.5 \mathrm{~cm}$. in diameter to $2 \mathrm{~cm}$. and raised about $0.4 \mathrm{~cm}$. Their color ranged from pearly to purple. On palpation the elevations were found to be thin walled, air-containing vesicles, which also contained a certain amount of fluid, so that the lungs were extremely crepitant. On section the lung was an even dark red, exuding a large amount of bloody fluid. The cut surface presented the cross section of tremendously dilated, or ruptured and confluent, alveoli. There was a small amount of mucus in the bronchi but no definite purulent exudate. On the right the interlobar space between the upper and middle lobes was obliterated by fine fibrous adhesions. The rest of the findings were unessential. Anatomical diagnosis: emphysema of lungs; congestion of lungs; passive congestion of liver; old pleuritis and pericarditis; edema.

38-39. L. B. has suffered from cough and repeated attacks of "asthma" for twenty-six years. He had pneumonia nine years ago. He is unable to do hard labor but is troubled with dyspnea only during the asthmatic attacks. The chest is barrel-shaped; the absolute cardiac dulness is obliterated. The level of the diaphragm changes only $1.5 \mathrm{~cm}$. with deep inspiration. The heart sounds are distant. Diagnosis: chronic bronchitis; chronic bronchial asthma; pulmonary emphysema.

42-43. F. B. complains of cough, shortness of breath and "choked sensation" on slight exertion. He is unable to do hard labor. The thorax is fixed. The anteroposterior diameter is unusually long. Numerous rhonchi are heard over the chest. Heart is normal. The brachial arteries are slightly thickened. Diagnosis: chronic bronchitis; pulmonary emphysema.

47. F. G. has suffered from cough and weakness for years. The chest is markedly pigeon-shaped, with unusually long anteroposterior diameter. The absolute cardiac dulness is completely obliterated. Musical rhonchi are heard over the chest. There is a very slight excursion of the diaphragm on deep inspiration. The heart is normal. Diagnosis: chronic bronchitis; pulmonary emphysema.

73. D. S. has suffered from repeated attacks of cough with productive expectoration for five to ten years. During the past year there has been increasing dyspnea. Patient was dyspneic at the time of test. The thorax did not move with respiration and the costal angle was very wide. Expiration was markedly prolonged. Rhonchi and râles were heard over both bases. The heart was normal. Diagnosis: chronic bronchitis; emphysema.

79. F. L. complains of dyspnea on moderate exertion and of chronic cough. 
Thorax is barrel-shaped. The costal margin is wide. Hyperresonant percussion note is heard with obliteration of the cardiac dulness. No excursion of the diaphragm is observed. Scattered squeaks are heard over the posterior surface of the chest. The heart is normal. Diagnosis: chronic bronchitis; pulmonary emphysema.

111. A. B. entered the hospital complaining of weakness and of cough of several years' duration. Slight but distinct cyanosis of the lips and finger tips is noted. Chest is barrel-shaped and does not move with respiration. The anteroposterior diameter of the thorax is very long and the costal angle wide. The breath sounds are suppressed. The heart is normal. Diagnosis: chronic bronchitis; pulmonary emphysema.

165,183 . J. D. complains of moderate shortness of breath on slightest exertion. The thorax is fixed. The anteroposterior diameter of the chest is very large. The border of the diaphragm is very low, with practically no excursion on deep inspiration. The heart is normal. Diagnosis: pulmonary emphysema.

174. F. R. has suffered from cough and dyspnea on slight exertion for four years. The productive cough has been more marked in the morning. He has been unable to work during the past two years. Slight cyanosis of finger tips and lips is seen. The thorax is barrel-shaped and does not move with respiration. The absolute cardiac dulness is obliterated. Costal angle is wide. The border of the diaphragm is $18 \mathrm{~cm}$. below the angle of scapula and moves but slightly with deep inspiration. Numerous squeaks are heard over chest. Heart is normal. Diagnosis: chronic bronchitis; pulmonary emphysema.

175. L. A. had whooping cough fifteen years ago. Since that time he has been short of breath and suffering from a cough which was marked in the morning. He has been unable to do persistent and hard work. Ankles never have been swollen. There was at time of test slight cyanosis. The chest is flat, long and hyperresonant. The border of the lungs is $20 \mathrm{~cm}$. below the angle of scapula. The expiration is very prolonged. There are râles and squeaks throughout the entire chest. Lower ribs and costal angle move slightly toward the medial line with inspiration (Hoover's sign). Heart is normal. Diagnosis: chronic bronchitis; pulmonary emphysema.

225. F. S. had dyspnea following pneumonia in 1918, and frequent attacks of "asthma" with cough. Thorax is hyperresonant. The absolute cardiac dulness is obliterated. The level of the diaphragm is $12 \mathrm{~cm}$. below the angle of the scapula and moves but slightly with respiration. There are scattered râles and rhonchi over the chest. Diagnosis: chronic bronchitis.

235,238 . N. U. has been repeatedly admitted to the hospital during the past two years on account of bronchial asthma from which he has been suffering for over ten years. During the past two years he has been unable to do much work. Slight dyspnea with active respiratory muscles is present. Squeaks and scattered râles are heard over the entire chest. Diagnosis: bronchial asthma; chronic bronchitis; pulmonary emphysema. 
270, 428. M. C., at time of first test, had been suffering from "asthma" for 26 years during which time he had had difficulty with breathing and "wheezing." During the past 6 years his dyspnea and cough had been getting worse. No seasonal variation of condition noted. For 3 years he had been unable to do physical work because of the dyspnea. At the first test he was not capable of walking up as many as ten steps. He was forced to sleep on seven large pillows at night. There was moderate cyanosis of lips, tongue, nose and fingers. The neck was short and the accessory respiratory muscles were active. Breathing was labored with prolongation of expiration. The chest was barrel-shaped with very long anteroposterior diameter. The absolute cardiac dulness was obliterated. Position of diaphragm was very low with slight change during deep inspiration. Scattered squeaks were heard over both lungs. Hoover's sign was not present. The left border of cardiac dulness was in the 5 th space, $12 \mathrm{~cm}$. from midline.

At time of his second test about seven months later, his general condition was even more grave. He was in very severe respiratory distress. Although no definite cyanosis was noted at this time Hoover's sign was present. Diagnosis: pulmonary emphysema.

302. J. K. complains of cough of several years' duration and weakness. Barrel shaped chest which is very short is noted. Cardiac dulness is obliterated. Excursion of diaphragm is very slight. Breath sounds are very faint. Heart is normal. Diagnosis: chronic bronchitis; pulmonary emphysema.

323. T. M. has been suffering from continuous cough and frequent attacks of "asthma" together with weakness for the past 3 years. Lately he has been experiencing dyspnea and during the past 2 months has been unable to do any work. He is forced to sleep on 5 pillows. Marked cyanosis is present when patient is in flat position. Cyanosis is less marked in upright position. The breath sounds are not heard. No râles or squeaks are heard. The absolute cardiac dulness is obliterated. The expansion of the diaphragm is normal. No evidence of cardiac pathology is noted. Diagnosis: chronic bronchitis; pulmonary emphysema.

345. F. V. has been suffering from cough and difficulty in breathing for the past 7 years. He had influenza during the epidemic of 1917, with bloody sputum. He has been repeatedly admitted to the hospital with acute bronchitis or bronchopneumonia. Frequent attacks of angioneurotic edema have been observed in the patient. Slight cyanosis of the lips is present. The very large, almost completely fixed thorax is hyperresonant with scattered musical squeaks and a few râles over the base. Heart is normal. Diagnosis: chronic bronchitis; pulmonary emphysema.

346. V. U. has suffered for 20 years from cough and "asthma." He developed an increasing weakness and dyspnea which lately became so severe that he has been unable to walk. Marked cyanosis over entire skin surface is noted. Short funnel-shaped chest, with unusually long anteroposterior diameter is present. 
Heart is normal and orthodiagram does not reveal enlargement of the cardiac shadow. Diagnosis: chronic bronchitis; pulmonary emphysema.

379. J. C. has suffered from increasing dyspnea for the past 5 years. He has been coughing for two years. The chest is barrel-shaped and does not show excursion with respiration. The absolute cardiac dulness is obliterated. The level of the diaphragm is $8 \mathrm{~cm}$. below angle of scapula and moves $3 \mathrm{~cm}$. down after a long inspiration. Diagnosis: chronic bronchitis; pulmonary emphysema.

412. J. M. suffered from pneumonia 4 years ago. He stayed in bed for 3 months at that time and has felt weak since, so much so, that he was considered by a physician as a patient suffering from heart disease. He has had a cough for the past three and a half years and for the past two years has been unable to work. As soon as he lifts anything heavy he becomes "choked" and shortwinded. There is a bluish lividity over the lips and face. The neck is short and the respiration labored. Thorax is short with a long anteroposterior diameter. The absolute cardiac dulness is obliterated. Breath sounds are suppressed. Squeaks are heard over the posterior aspect of the chest. Diagnosis: pulmonary emphysema.

236, 237. J. L. is suffering from attacks of asthma which he has had for the last 11 years. For the last 2 years he has been unable to do hard work. The past month he has been unable to do any work whatever. The lips are cyanotic. The anteroposterior diameter of the chest is increased. Thorax is hyperresonant and the movements of the diaphragm are but slight on deep inspiration. Many coarse, squeaking and sibilant râles are heard. Diagnosis: bronchial asthma; chronic bronchitis; pulmonary emphysema.

359. C. H. has been suffering from cough and frequent attacks of asthma for 5 years. He has felt so weak during the past 2 years that he has been unable to work. At time of test he was suffering from orthopnea and dyspnea and felt so weak that he was unable to walk. The chest was flat and long and hyperresonant. The absolute cardiac dulness was obliterated. The excursion of the diaphragm was but slight (Hoover's sign absent). Diagnosis: bronchial asthma; pulmonary emphysema. 